\title{
Sensitivity of Phacidiopycnis spp. Isolates from Pome Fruit to Six Pre- and Postharvest Fungicides
}

Emran Md. Ali, Laxmi K. Pandit, Katie A. Mulvaney, and Achour Amiri, ${ }^{\dagger}$ Washington State University, Department of Plant Pathology, Tree Fruit Research and Extension Center, Wenatchee 98801

\begin{abstract}
Phacidiopycnis washingtonensis and $P$. pyri cause speck rot and Phacidiopycnis rot on apple and pear, respectively. Infection occurs in the orchard and remains latent, and symptoms appear after months of storage. Decay management relies on orchard sanitation and pre- and postharvest fungicides. In a 2017 survey, speck rot accounted for $6.4 \%$ of apple decay in central Washington, whereas Phacidiopycnis rot accounted for 3.9 and $6.7 \%$ of total pear decay in Washington and Oregon, respectively. Sensitivities of baseline populations of $110 \mathrm{P}$. washingtonensis and 76 $P$. pyri isolates collected between 2003 and 2005 to preharvest fungicides pyraclostrobin (PYRA) and boscalid (BOSC) and to postharvest fungicides thiabendazole (TBZ), fludioxonil (FDL), pyrimethanil (PYRI), and difenoconazole (DFC) were evaluated using a mycelial growth inhibition assay. Mean effective concentrations necessary to inhibit $50 \%$

growth $\left(\mathrm{EC}_{50}\right)$ of $P$. washingtonensis were $0.1,0.3,0.8,1.8,2.1$, and $4.8 \mu \mathrm{g} / \mathrm{ml}$ for FDL, PYRI, TBZ, DFC, PYRA, and BOSC, respectively. Respective mean $\mathrm{EC}_{50}$ values for $P$. pyri were $0.2,0.6,1.6,1.1,0.4$, and $1.8 \mu \mathrm{g} / \mathrm{ml}$. The sensitivity of exposed $P$. washingtonensis and $P$. pyri populations collected in 2017 revealed potential shifts toward BOSC and PYRA resistance. The efficacy of the six fungicides to control isolates of each pathogen with different in vitro sensitivity levels was evaluated on apple and pear fruit. FDL, DFC, and PYRI controlled both Phacidiopycnis spp. regardless of their $\mathrm{EC}_{50}$ values after 5 months of storage at $0^{\circ} \mathrm{C}$ in a regular atmosphere. The consistent occurrence of $P h a-$ cidiopycnis spp. will require continuous monitoring and development of disease management strategies based on fungicide phenotypes and efficacy of existing fungicides assessed herein.
\end{abstract}

Speck rot, caused by the ascomycete fungus Phacidiopycnis washingtonensis, is an emerging pome fruit pathogen reported for the first time first in 2005 on apple in Washington State (Kim and Xiao 2006; Xiao et al. 2005). It has since been reported on apple in Germany and Denmark (Weber 2011) and Chile (Díaz et al. 2016), on persimmon in Italy (Garibaldi et al. 2010), and on pacific Madrone in the U.S. Pacific Northwest (PNW) (Elliott et al. 2014). The pathogen is still quarantined in several other countries. The fungus causes fruit rot during storage and twig dieback on crab apple trees commonly used as pollinizers in Washington State (Xiao et al. 2005). In a survey conducted on Red Delicious apple in Washington State between 2003 and 2005, speck rot occurred in about $20 \%$ of the surveyed lots and accounted for 4 and $3 \%$ of total decay, respectively (Kim and Xiao 2006). The typical symptoms of speck rot on apple fruit during storage are stem-end and calyx-end rots (Xiao et al. 2005). The decayed tissue is firm to spongy, with light-brown lesions which can be confused with symptoms of gray mold or Sphaeropsis rot at early infection stages. When the disease advances, the fruit remain firm but the decayed area turns black and, under humid conditions, can produce abundant white pycnidia (Giraud et al. 2001; Kim and Xiao 2006). The fungus survives on twigs and cankers in orchards, and will infect fruit via inoculum released and dispersed by water splash and insects (Sikdar et al. 2013; Xiao et al. 2009). Infections remain latent and symptoms are usually visible on fruit stored for 5 months or longer.

The discomycete $P$. pyri (teleomorph Potebniamyces pyri) was reported decades ago on several Pyrus, Malus, and other tree species worldwide (Brooks 1928; Cannon et al. 1985; Dennis 1978; Ficke and Agraring 1982; Southee and Brooks 1926). The species Phacidiopycnis pyri was first associated with bark and branch cankers, and has been recognized to cause decay on fruit in India and Europe (Giraud et al. 2001; Sharma 1991; Snowdon 1992). In Washington State, $P$. pyri was reported to cause postharvest disease on d'Anjou pear in 2002 and accounted for 23 to $34 \%$ of total decay statewide (Xiao and Boal 2002, 2004). The disease has also been reported in British

${ }^{\dagger}$ Corresponding author: A. Amiri; E-mail: a.amiri@wsu.edu

Accepted for publication 28 September 2017.

(c) 2018 The American Phytopathological Society
Columbia, Canada in 2010 (Sholberg et al. 2010). P. pyri is characterized by microcyclic conidiation, capable of germinating by budding or through mycelial growth, common to many fungal species (Liu and Xiao 2005; Potebnia 1912). The fungus is believed to survive on cankers and necrosis on trees, and viable conidia are released and water dispersed during the pear growing season (DiCosmo et al. 1984). D'Anjou pear fruit are stored at -1 to $0.5^{\circ} \mathrm{C}$ in controlled atmospheres ( 1 to $2 \% \mathrm{O}_{2}$ and $0.5 \% \mathrm{CO}_{2}$ ). Low temperatures slow but do not completely inhibit the germination of $P$. pyri (Liu and Xiao 2005), whereas the role of controlled atmospheres $\left(1\right.$ to $2 \% \mathrm{O}_{2}$ and $\left.0.5 \% \mathrm{CO}_{2}\right)$ on $P$. pyri germination and growth has not been investigated. After several months of storage, symptoms of Phacidiopycnis rot can become visible as stem-end, calyx-end, or wound rots. The initial, firm brown lesion turns blackish colored and can develop dark green to black pycnidia (Giraud et al. 2001).

In addition to orchard sanitation achieved by pruning diseased branches and cankers and removal of mummified fruit on trees and pollinizers, pre- and postharvest fungicide applications are the most efficient way to control Phacidiopycnis rots on apple and pear. In addition to the multisite fungicide ziram, three single-site fungicides - thiophanate-methyl, boscalid (BOSC), and pyraclostrobin (PYRA) - are used frequently by Washington State growers in the last 2 weeks preceding harvest to control Phacidiopycnis rots and other diseases. After harvest, thiabendazole (TBZ), pyrimethanil (PYRI), or fludioxonil (FDL) have been used postharvest for years to control apple and pear diseases. Difenoconazole (DFC), premixed with FDL as Academy (Syngenta Crop Protection, Greensboro, NC), was registered in 2016 but has not been used frequently. The efficacy of preharvest applications of ziram and postharvest application of TBZ was evaluated in a single study on $P$. pyri, with mixed results (Xiao and Boal 2008). In addition to the unknown efficacy of most of the pre- and postharvest fungicides to control $P$. washingtonensis and $P$. pyri, it still unknown whether sensitivity shifts have occurred in populations of these two pathogens exposed for decades to these fungicides. Therefore, the objectives of this study were to (i) determine whether $P$. washingtonensis and $P$. pyri are currently causing disease on pome fruit in the PNW via a survey of Washington State and Oregon, (ii) determine the sensitivity of baseline and exposed populations of $P$. washingtonensis and $P$. pyri to six pre- and postharvest fungicides, and (iii) evaluate the efficacy of these fungicides in vivo. 


\section{Materials and Methods}

Prevalence of $P$. washingtonensis and $P$. pyri during the 2016-17 season. A survey of $P$. washingtonensis and $P$. pyri was conducted in 2017 in central Washington and the Hood River area of northern Oregon were conducted from February to May of 2017 (Fig. 1). In total, 16 apple packinghouses, including 149 growers lots (orchards), were surveyed from nine counties representing major apple production areas in Washington State. For pear, nine packinghouses, including 41 growers lots in Central Washington and 74 lots from North Oregon, were surveyed. For each grower lot, 50 decayed apple or pear fruit originating from each orchard were randomly collected on the packing line, laid on clamshells to avoid contact between fruit, and transferred to the laboratory for further disease characterization. A minimum of 10 grower lots were surveyed for each packinghouse. Following an initial visual symptom assessment, pure cultures were made from all decayed fruit. Fruit were bisected with an ethanol-sterilized knife, then cut into two halves. A small piece ( 3 by $3 \mathrm{~mm}$ ) of the flesh taken at the margin of decayed and healthy tissue inside the fruit was transferred to the center of a Petri plate containing general isolation (GI) medium (19.5 $\mathrm{g}$ of potato dextrose agar, $7.5 \mathrm{~g}$ of agar, $200 \mathrm{mg}$ of streptomycin, and $100 \mathrm{mg}$ of ampicillin in 1 liter of distilled water). Plates were incubated in the dark at $22^{\circ} \mathrm{C}$ for 6 days and characterization of the pathogens was conducted as described by Xiao et al. (2005) and Xiao and Boal (2004). Pure cultures of all $P$. washingtonensis and $P$. pyri isolates were made by transferring a 6-mm plug from the edge of the GI colonies to potato dextrose agar (PDA) plates and incubated as above until they were used for fungicide sensitivity test as described below.

Fungal populations. Two separate populations were used for analysis. Baseline populations of 110 P. washingtonensis and 76 $P$. pyri isolates were collected between 2003 and 2005. They were never exposed to most common pre- and postharvest fungicides, except for thiophanate-methyl and TBZ. A second group of exposed populations consisted of $100 \mathrm{P}$. washingtonensis and $50 \mathrm{P}$. pyri isolates collected in 2017. These had been previously exposed to all fungicides tested in this study, except DFC, based on grower and packer spray records. Baseline isolates were kept in $20 \%$ glycerol at $-80^{\circ} \mathrm{C}$
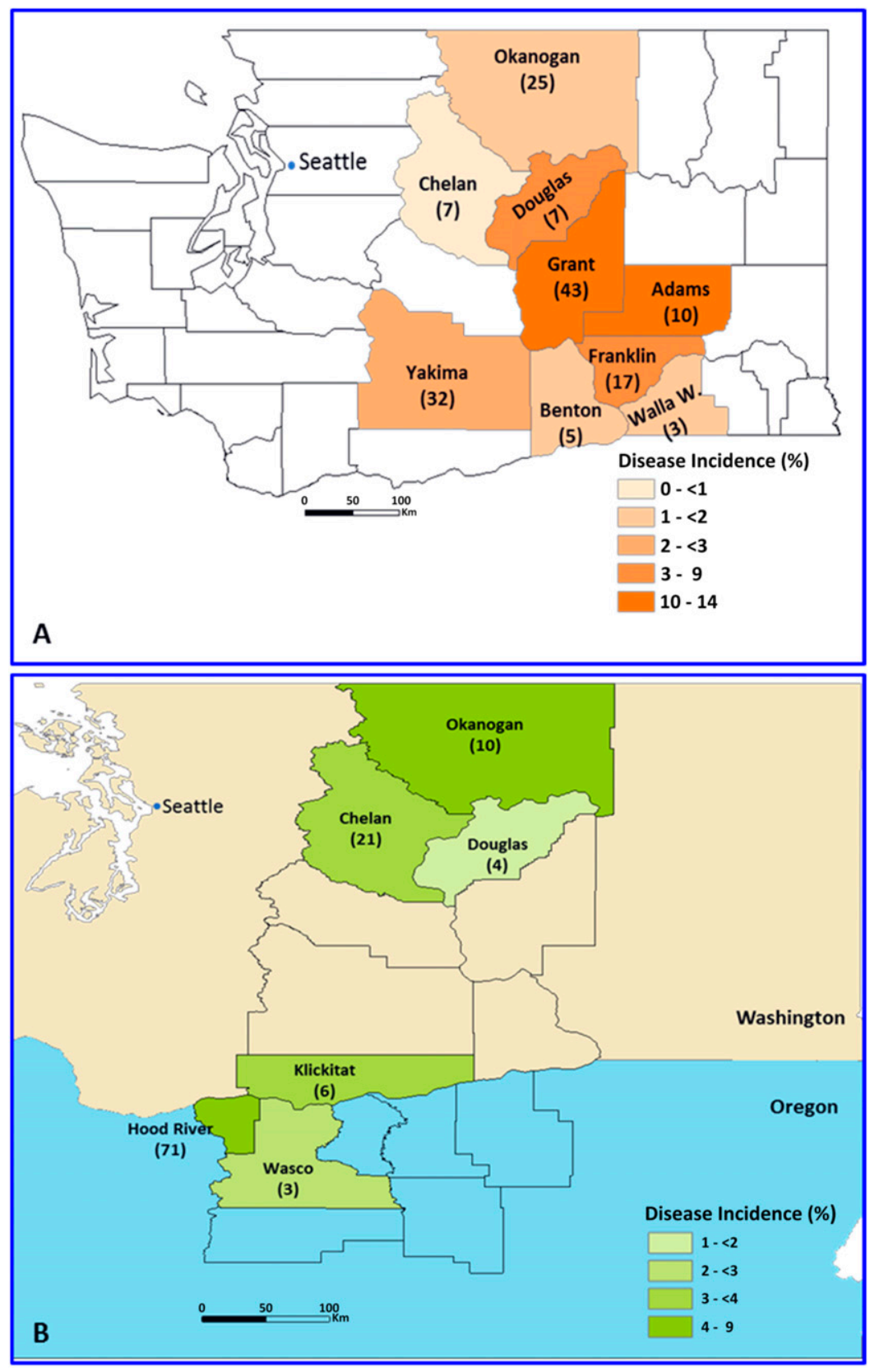

Fig. 1. A, Frequency distribution of Phacidiopycnis washingtonensis in Washington State and B, P. pyri incidences in Washington and Oregon during the 2016-17 season. In total, 149 and 41 apple and pear grower lots, respectively, were surveyed in Washington State, and 74 pear grower lots were surveyed in Oregon. The number in parentheses below each county name indicates the number of grower lots surveyed in each county. 
at the Washington State University Tree Fruit Research and Extension Center pathology laboratory and grown on PDA medium for 7 to 10 days at $22^{\circ} \mathrm{C}$. Exposed isolates were collected and maintained as described above.

Fungicides. Sensitivities of the baseline and exposed populations of $P$. washingtonensis and $P$. pyri were evaluated to two preharvest fungicides-BOSC (Endura; BASF Crop Protection, Research Triangle Park, NC) and PYRA (Cabrio EG; BASF Crop Protection)—and four postharvest fungicides: TBZ (Mertect 340F; Syngenta Crop Protection), FDL (Medallion WDG; Syngenta Crop Protection), PYRI (Penbotec 400SC; Janssen Pharmaceutica NV, Beerse, Belgium), and DFC (Thesis; Syngenta Crop Protection). The fungicides were dissolved in sterile distilled water, stored at $4{ }^{\circ} \mathrm{C}$ for no more than 30 days, and used for fungicide sensitivity tests as described below.

Fungicide sensitivity evaluation. Sensitivity tests were conducted using a mycelial growth inhibition assay. Sensitivities to PYRA, TBZ, FDL, and DFC were assessed on PDA medium, whereas the sensitivities to PYRI and BOSC were assessed on L-asparagine agar (ASPA) and minimal medium (MM), respectively. ASPA contained $1 \mathrm{~g}$ of $\mathrm{K}_{2} \mathrm{HPO}_{4}, 1 \mathrm{~g}$ of $\mathrm{MgSO}_{4}, 0.5 \mathrm{~g}$ of $\mathrm{KCl}, 10 \mathrm{mg}$ of $\mathrm{FeSO}_{4}, 2 \mathrm{~g}$ of asparagine, $22 \mathrm{~g}$ of glucose, and $15 \mathrm{~g}$ of agar in 1.0 liter of distilled water (Hilber and Schüepp 1996). The MM contained $1.5 \mathrm{~g}$ of $\mathrm{K}_{2} \mathrm{HPO}_{4}$, $2 \mathrm{~g}$ of $\mathrm{KH}_{2} \mathrm{PO}_{4}, 0.5 \mathrm{~g}$ of MgSO $4,1 \mathrm{~g}$ of $\left(\mathrm{NH}_{4}\right)_{2} \mathrm{SO}_{4}, 2 \mathrm{~g}$ of yeast extract, $10 \mathrm{~g}$ of glucose, and $12.5 \mathrm{~g}$ of agar in 1.0 liter of distilled water (Hu et al. 2011). To test for sensitivity in the baseline populations, autoclaved media were cooled to $50^{\circ} \mathrm{C}$ and fungicides were added from stocks to obtain final concentrations of $0.0,0.001,0.01,0.1$, and $1.0 \mu \mathrm{g} / \mathrm{ml}$ for FDL; $0.0,0.01,0.1,1.0$, and $10.0 \mu \mathrm{g} / \mathrm{ml}$ for TBZ and BOSC; and 0.0, 0.005, $0.05,0.05$, and $5.0 \mu \mathrm{g} / \mathrm{ml}$ for PYRA, DFC, and PYRI. Amended media were poured into $90-\mathrm{mm}$ Petri plates and allowed to solidify. Salicylhydroxamic acid, dissolved in methanol, was added to autoclaved media at a final concentration of $100 \mu \mathrm{g} / \mathrm{ml}$ (Amiri et al. 2010) when testing for PYRA to inhibit the alternative respiration pathway.

To test for sensitivity in the baseline $P$. washingtonensis and $P$. pyri populations, two plugs taken from the edge of a growing 10-day-old colony of each isolate were transferred upside down to fungicideamended plates and nonamended control plates. Plates were incubated for 5 days at $22^{\circ} \mathrm{C}$ before measuring the radial growth in two directions. Four plates were used for each fungicide concentration with a given pathogen and the trial was conducted twice.

Sensitivities of the exposed populations collected in 2017 were tested using a mycelial growth inhibition assay on the same media mentioned above, amended with a discriminatory dose of each fungicide (Table 1). These doses were determined $25 \%$ above the average effective concentrations necessary to inhibit $50 \%$ growth $\left(\mathrm{EC}_{50}\right)$ values of the baseline populations. Fungicide sensitivity tests were conducted as described for the baseline populations, except that two replicateplates were used per isolate-fungicide combination. Mycelial growth measured after 5 days at $22^{\circ} \mathrm{C}$ was computed and expressed as percent relative growth inhibition (RGI) compared with the control. Isolates with an RGI $\leq 49 \%$ were considered to have reduced sensitivity.

Control of $\boldsymbol{P}$. washingtonensis and $\boldsymbol{P}$. pyri on detached fruit with pre- and postharvest fungicides. The efficacy of BOSC, PYRA, TBZ,
PYRI, FDL, and DFC against isolates of $P$. washingtonensis and $P$. pyri with different levels of sensitivity in vitro was assessed on detached fruit. For each pathogen, three isolates, including one isolate with low, one with medium, and one with highest $\mathrm{EC}_{50}$ values, were selected for each fungicide. Apple fruit (Jonagold) and pear fruit (d'Anjou) were surface disinfected in $0.8 \%$ sodium hypochlorite for $2 \mathrm{~min}$, washed twice with sterile water, then air dried. Fruit were wounded twice near the stem-end area with a sterile needle (1.5 $\mathrm{mm}$ in diameter, $3 \mathrm{~mm}$ deep) and dipped for $30 \mathrm{~s}$ in fungicide suspensions of formulated BOSC (Endura), PYRA (Cabrio), TBZ (Mertect), PYRI (Penbotec), FDL (Scholar SC), and DFC (Thesis) at label rates of $0.6 \mathrm{~g} / \mathrm{liter}, 0.7 \mathrm{~g} / \mathrm{liter}, 0.5 \mathrm{ml} / \mathrm{liter}$, $1.2 \mathrm{ml} /$ liter, $0.8 \mathrm{ml} /$ liter, and $0.8 \mathrm{ml} /$ liter, respectively. Control fruit were wounded and dipped in sterile water. Fruit were left for $4 \mathrm{~h}$ at room temperature and each wound was inoculated with a $25-\mu l$ droplet of spore suspension $\left(5 \times 10^{4}\right.$ spores $\left./ \mathrm{ml}\right)$ for $P$. washingtonensis and a 5-mm-diameter mycelial plug placed upside down for $P$. pyri isolates. Sporulation of $P$. pyri is very difficult on existing artificial media and initial trials conducted with yeast-phase of the pathogen resulted in several contaminations (data not shown). Therefore, the use of mycelial plugs for $P$. pyri fruit inoculation is relevant and reflects in vitro sensitivity because $\mathrm{EC}_{50}$ values were determined based on mycelial growth inhibition. Four replicate fruit were used for each isolate and fungicide combination and the trial was conducted twice. Inoculated fruit were placed on sterile aluminum trays in plastic boxes containing $200 \mathrm{ml}$ of sterile water, and stored in sealed bags at $0^{\circ} \mathrm{C}$ in a regular atmosphere. Disease incidence and severity were determined relative to untreated control fruit after 4 and 5 months of storage for $P$. pyri and P. washingtonensis, respectively.

Data analysis. Fungicide concentrations used for in vitro sensitivities of the baseline populations were log-transformed and plotted against probit-transformed percent inhibitions to calculate $\mathrm{EC}_{50}$ values. Variation factors $(\mathrm{VF})$ were calculated as the highest $\mathrm{EC}_{50}$ value divided by the lowest $\mathrm{EC}_{50}$ value within the population. The incidences of $P$. washingtonensis and $P$. pyri were calculated for each county, the data were transferred into a Geographic Information System, and disease distribution maps were produced using spatial analysis and geoprocessing techniques of ArcMap in ArcGIS (10.4.1; ESRI, Redlands, CA). In vivo efficacy data from the two runs for each isolate and fungicide treatment combination were averaged and used to calculate disease incidence and severity, which were subjected to an analysis of variance and mean separations using Student's $t$ test at $P<0.05$ in SAS software (version 9.2; SAS Institute Inc., Cary, NC). Pearson correlation coefficients were calculated to estimate the correlation of $\mathrm{EC}_{50}$ values between tested fungicides.

\section{Results}

Prevalence and distribution of $\boldsymbol{P}$. washingtonensis and $\boldsymbol{P}$. pyri in 2017. Both pathogens continue to cause decay on apple and pear postharvest. Speck rot, caused by $P$. washingtonensis, was found in 59 of the 140 lots surveyed $(42.1 \%)$ and a statewide average of $6.4 \%$ of total decay on apple. Incidence ranged from 2 to $84 \%$ between lots, with a majority of $72 \%$ of lots showing a speck rot incidence lower than $10 \%$. Speck rot was not detected in lots surveyed in Chelan County, and was found at frequencies lower than $1 \%$ in Walla Walla,

Table 1. Fungicides, media used to evaluate fungicide sensitivity of baseline populations of Phacidiopycnis washingtonensis and $P$. pyri, and discriminatory doses used to assess fungicide sensitivity of exposed populations

\begin{tabular}{|c|c|c|c|c|c|c|}
\hline \multirow[b]{2}{*}{ Fungicides } & \multirow[b]{2}{*}{ Trade name } & \multirow[b]{2}{*}{ a.i. $(\%)$} & \multirow[b]{2}{*}{ Group $^{\mathbf{b}}$} & \multirow[b]{2}{*}{ Media $^{c}$} & \multicolumn{2}{|c|}{ Discriminatory dose $(\mu \mathrm{g} / \mathrm{ml})^{\mathrm{a}}$} \\
\hline & & & & & P. washingtonensis & P. pyri \\
\hline Boscalid (BOSC) & Endura & 70 & SDHI & MM & 5.00 & 5.00 \\
\hline Fludioxonil (FDL) & Medallion WP & 50 & PP & PDA & 0.50 & 0.75 \\
\hline Difenoconazole (DFC) & Thesis & 32.7 & DMI & PDA & 0.50 & 2.00 \\
\hline Pyraclostrobin (PYRA) & Cabrio & 20 & QoI & PDA & 2.00 & 0.50 \\
\hline Pyrimethanil (PYRI) & Scala SC & 54.6 & AP & ASPA & 0.75 & 0.75 \\
\hline Thiabendazole (TBZ) & Mertect & 50 & $\mathrm{MBC}$ & PDA & 0.75 & 3.00 \\
\hline
\end{tabular}

${ }^{a}$ Discriminatory doses used to evaluate sensitivity of exposed populations of both pathogens collected in 2017.

${ }^{\mathrm{b}}$ Chemical groups SDHI, PP, DMI, QoI, AP, and MBC indicate succinate fungicides from dehydrogenase inhibitor, phenylpyrrole, demethylation inhibitor, quinone-outside inhibitors, anilinopyrimidines, and methyl benzimidazole carbamate groups, respectively.

${ }^{c}$ PDA, ASPA, and MM indicate potato dextrose agar, L-asparagine agar, and minimal medium, respectively. 
Okanogan, and Benton Counties, whereas Grant and Adams Counties showed the highest frequencies of 10.9 and $13.8 \%$, respectively (Fig. 1A). Overall, 57 pear lots of the 115 surveyed (49.5\%) showed P. pyri, with statewide averages of 3.9 and $6.7 \%$ of total decay in Washington and Oregon, respectively (Fig. 1B). In Washington, P. pyri was found in $60 \%$ of the 41 lots surveyed, with frequencies ranging from $0.7 \%$ in Chelan County to $12.1 \%$ in Okanogan County (Fig. 1B). In Oregon, P. pyri was found in $58 \%$ of the 74 lots surveyed, with frequencies ranging from 2 to $7.1 \%$ in Wasco and Hood River Counties, respectively (Fig. 1B).

Baseline in vitro sensitivities of $\boldsymbol{P}$. washingtonensis and $\boldsymbol{P}$. pyri. The mean $\mathrm{EC}_{50}$ values of $P$. washingtonensis were $0.1,0.3,0.8,1.8$, 2.1 , and $4.8 \mu \mathrm{g} / \mathrm{ml}$ for FDL, PYRI, TBZ, DFC, PYRA, and BOSC, respectively (Table 2). The VF in $P$. washingtonensis were higher than 100 for all fungicides and ranged from 210 for FDL to 3,080 for BOSC (Table 2). Overall, a similar sensitivity trend was observed for P. pyri, although the mean $\mathrm{EC}_{50}$ values were lower compared with $P$. washingtonensis, except for FDL and PYRI. The ranges of $\mathrm{EC}_{50}$ values in $P$. pyri were narrower compared with $P$. washingtonensis, which resulted in VF lower than 100 for all fungicides except PYRA (Table 2).

In most cases, there were no significant correlations between the $\mathrm{EC}_{50}$ values for all fungicides tested. In $P$. washingtonensis, moderately significant correlations were observed between FDL and TBZ $(r=0.304)$ and between FDL and PYRA $(r=0.214)$, whereas negative correlations were observed between DFC and PYRA $(r=-0.032)$ and $\mathrm{DFC}$ and BOSC ( $r=-0.022)$. In $P$. pyri, moderately significant correlations were observed between BOSC and each of TBZ $(r=0.327)$, DFC ( $r=0.466)$, and PYRI ( $r=0.416)$ (Table 3).

Sensitivities of $P$. washingtonensis and $P$. pyri exposed populations. In all, 100 P. washingtonensis and 50 P. pyri isolates collected in 2017 were tested for their sensitivity using a discriminatory dose for each fungicide (Table 1). A majority of isolates ( $>80 \%)$ of both pathogens had an RGI $\leq 49 \%$ for BOSC and PYRA compared with only $28 \%$ for TBZ

Table 2. Mean and range of effective concentration inhibiting 50\% $\left(\mathrm{EC}_{50}\right)$ growth of Phacidiopycnis washingtonensis and P. pyri ${ }^{\mathrm{a}}$

\begin{tabular}{|c|c|c|c|c|c|c|}
\hline \multirow[b]{3}{*}{ Fungicides } & \multicolumn{3}{|c|}{ P. washingtonensis } & \multicolumn{3}{|c|}{ P. pyri } \\
\hline & \multicolumn{2}{|c|}{$\mathrm{EC}_{50}(\mu \mathrm{g} / \mathrm{ml})$} & \multirow[b]{2}{*}{ VF } & \multicolumn{2}{|c|}{$E_{50}(\mu \mathrm{g} / \mathrm{ml})$} & \multirow[b]{2}{*}{ VF } \\
\hline & Mean & Range & & Mean & Range & \\
\hline Fludioxonil & 0.10 & $0.009-1.89$ & 210 & 0.24 & $0.01-0.85$ & 85 \\
\hline Pyrimethanil & 0.32 & $0.020-9.83$ & 983 & 0.61 & $0.02-1.62$ & 81 \\
\hline Thiabendazole & 0.84 & $0.010-4.07$ & 407 & 1.57 & $0.04-2.98$ & 75 \\
\hline Difenoconazole & 1.80 & $0.020-14.2$ & 710 & 1.09 & $0.20-2.97$ & 15 \\
\hline Pyraclostrobin & 2.12 & $0.007-14.14$ & 2,020 & 0.38 & $0.01-2.18$ & 218 \\
\hline Boscalid & 4.80 & $0.010-30.80$ & 3,080 & 1.81 & $0.13-9.48$ & 73 \\
\hline
\end{tabular}

${ }^{\mathrm{a}}$ Mean $\mathrm{EC}_{50}$ values from 110 P. washingtonensis and 76 P. pyri isolates. Variation factor $(\mathrm{VF})$ was calculated by dividing the highest $\mathrm{EC}_{50}$ value by the lowest $\mathrm{EC}_{50}$ value within the population for each fungicide.
(Fig. 2). For DFC and PYRI, more than $90 \%$ of isolates from both pathogens had an RGI $>50 \%$ whereas, for FDL, $95 \%$ of $P$. washingtonensis and all $P$. pyri isolates had an RGI $>75 \%$.

Efficacy of fungicides for Phacidiopycnis rot control on detached fruit. FDL and DFC, applied as a preventive treatment according to the label, fully controlled $P$. washingtonensis and $P$. pyri isolates regardless of their in vitro $\mathrm{EC}_{50}$ values after 5 and 4 months of storage, respectively, at $0.5^{\circ} \mathrm{C}$ in a normal atmosphere (Table 4). PYRI controlled all $P$. pyri isolates (Table 4 ) after 4 months of storage and $P$. washingtonensis isolates until up to 3 months (data not shown) but failed to control $P$. washingtonensis isolates regardless of their in vitro $\mathrm{EC}_{50}$ value after 5 months of storage (Table 4). Thus, speck rot

\section{P. washingtonensis}
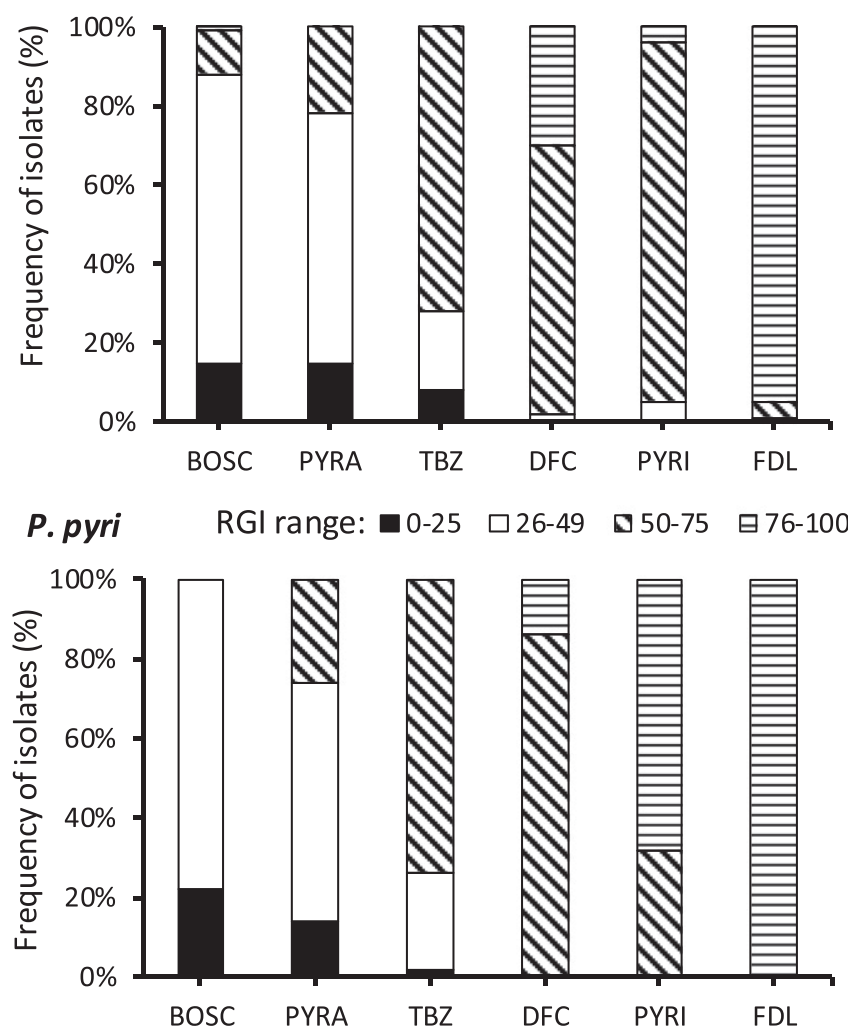

Fig. 2. Frequency of Phacidiopycnis washingtonensis and $P$. pyri isolates collected in 2017 with different relative growth inhibition (RGI) relative to the control on media amended with discriminatory doses of each fungicide. BOSC = boscalid, PYRA = pyraclostrobin, $\mathrm{TBZ}=$ thiabendazole, $\mathrm{DFC}=$ difenoconazole, $\mathrm{PYRI}=$ pyrimethanil, and $\mathrm{FDL}=$ fludioxonil. Isolates with an $\mathrm{RGI} \leq 49 \%$ (black and white bars) are considered to have reduced sensitivity.

Table 3. Correlation between effective concentrations necessary to inhibit 50\% growth $\left(\mathrm{EC}_{50}\right)$ values of boscalid (BOSC), difenoconazole (DFC), fludioxonil (FDL), pyraclostrobin (PYRA), pyrimethanil (PYRI), and thiabendazole (TBZ) in Phacidiopycnis washingtonensis and P. pyri isolates

\begin{tabular}{|c|c|c|c|c|c|c|}
\hline \multirow[b]{2}{*}{ Pathogen, fungicide } & \multirow[b]{2}{*}{ FRAC group } & \multicolumn{5}{|c|}{ Correlation with } \\
\hline & & TBZ (1) ${ }^{\mathrm{a}}$ & PYRA (11) & BOSC (7) & DFC (3) & PYRI (9) \\
\hline \multicolumn{7}{|l|}{ P. washingtonensis } \\
\hline FDL & 12 & $0.304 *$ & $0.214^{*}$ & 0.016 & 0.032 & 0.019 \\
\hline TBZ & 1 & $\ldots$ & 0.167 & 0.166 & -0.032 & 0.151 \\
\hline PYRA & 11 & 0.167 & $\ldots$ & 0.177 & 0.049 & 0.002 \\
\hline BOSC & 7 & 0.166 & 0.177 & $\ldots$ & -0.022 & 0.053 \\
\hline \multicolumn{7}{|l|}{ P. pyri } \\
\hline FDL & 12 & 145 & 0.126 & 0.201 & 0.205 & 0.091 \\
\hline TBZ & 1 & $\ldots$ & 0.088 & $0.327 *$ & 0.134 & 0.191 \\
\hline PYRA & 11 & 0.088 & $\ldots$ & 0.197 & 0.162 & 0.197 \\
\hline BOSC & 7 & $0.327 *$ & 0.197 & $\ldots$ & $0.466^{*}$ & $0.416^{*}$ \\
\hline
\end{tabular}

a Numbers in parentheses indicate the FRAC code for each fungicide. Spearman correlation coefficient $r$ was calculated from the $\mathrm{EC}_{50}$ values of 110 Phacidiopycnis washingtonensis and $76 P$. pyri isolates. An asterisk (*) indicates significant $P$ values for corresponding coefficients. 
incidence ranged from 37.5 to $87.5 \%$ after 5 months of storage on apple fruit treated with PYRI at harvest. Interestingly, the isolate Pwa2665 , with a PYRI EC ${ }_{50}$ value of $1.86 \mu \mathrm{g} / \mathrm{ml}$, had a significantly higher disease incidence and severity than Pwa-2649, with an EC $_{50}$ of $9.83 \mu \mathrm{g} / \mathrm{ml}$ (Table 4). TBZ, BOSC, and PYRA applied at label rates at harvest failed to control $P$. washingtonensis and $P$. pyri isolates regardless of their in vitro $\mathrm{EC}_{50}$ values after 5 and 4 months of storage, respectively. Overall, disease incidence and severity was slightly lower in TBZ- and PYRI-treated fruit compared with BOSC, whereas no difference was noticed between these three fungicides in P. pyri (Table 4). BOSC was ineffective after 1 month of storage, whereas PYRA and TBZ controlled $P$. washingtonensis isolates for 3 months (data not shown) before their efficacy started to decrease.

\section{Discussion}

$P$. washingtonensis and $P$. pyri continue to be widespread in the PNW and to cause speck and Phacidiopycnis rots on apple and pear postharvest, as documented herein. Although speck rot accounted for a small portion of total statewide decay, it was found in eight of nine counties and in $42 \%$ of grower lots surveyed in Washington State in 2017. Additionally, the pathogen is quarantined and previously prevented trade of west coast fruit with China in 2015. Moreover, 27\% of the lots that showed speck rot had an incidence higher than $10 \%$ and incidences as high as 40 to $80 \%$ were found in some lots. These frequencies are higher than those reported in 2006, when speck rot accounted for 1 to $4 \%$ of total decay statewide and was only found in 17 to $26 \%$ of grower lots surveyed between 2003 and 2005 (Kim and Xiao 2006). It is possible that the larger 2017 survey of 149 orchards, compared with 26 to 80 in the previous survey (Kim and Xiao 2006), accounts for some of the increased speck rot occurrence. These findings suggest that the management practices such as crab apple tree pruning, removal of mummies, and fungicide sprays implemented since the pathogen was first reported may not be adequately suppressing speck rot. Future studies may be necessary to determine whether this pathogen continues to spread and adapt to the west coast pome fruit-growing region. In contrast, the occurrence of Phacidiopycnis rot on pear seems to be lessening because it only accounted for 3.9\% of total decay in Washington in 2017, compared with $34.1 \%$ in 2002 (Xiao and Boal 2004). The higher number of lots (115) surveyed in 2017 (compared with only 26 in 2001), the timing of sampling (packed versus repacked fruit), and different weather conditions may explain some of this variability. In the present study, the incidence of Phacidiopycnis rot was slightly higher (7\%) in Oregon compared with Washington (3.9\%). Lots surveyed in Oregon were all from the Hood River, a region known to have a rainfall three to four times higher than central Washington. It is likely that increased humidity and extended wetness duration in this growing region can be more conducive for disease because periods of 6 to $8 \mathrm{~h}$ of wetness are required for P. pyri germination (Liu and Xiao 2005).

The phenylpyrrole FDL had the highest intrinsic activity against $P$. washingtonensis and $P$. pyri, greater than any of the five other fungicides. It had the lowest $\mathrm{EC}_{50}$ values and $\mathrm{VF}$ in the baseline populations of both pathogens and almost all isolates collected in 2017 showed a high level of sensitivity to FDL. The observed high in vitro activity translated into an absolute control on detached fruit because all $P$. pyri and $P$. washingtonensis isolates remained symptomless after 4 and 5 months of storage, respectively, regardless of their in vitro sensitivity levels. FDL has been used frequently in the last 5 to 10 years to control major postharvest diseases in Washington State after resistance to PYRI was reported in Penicillium expansum (Xiao et al. 2011). FDL is a locally systemic fungicide which may reduce the exposure time of Phacidiopycnis washingtonensis and $P$. pyri quiescent infections originating from orchards, and therefore, lower selection pressure. FDL has low risk for fungicide resistance development and even in "high-risk" pathogens such as Penicillium expansum and Botrytis cinerea that are known to develop resistance to fungicides with various modes of action. However, resistance to FDL has been rare and reported at very low frequencies (Amiri et al. 2017; Fernández-Ortuño et al. 2013;

Table 4. Control of Phacidiopycnis washingtonensis and P. pyri isolates exhibiting different in vitro sensitivity levels with commercial fungicides on detached apple and pear fruit

\begin{tabular}{|c|c|c|c|c|}
\hline Pathogen, fungicide & Isolate $^{\mathbf{a}}$ & $\mathrm{EC}_{50}(\mu \mathrm{g} / \mathrm{ml})^{\mathrm{b}}$ & Incidence $(\%)^{\mathrm{c}}$ & Severity $(\%)^{d}$ \\
\hline \multicolumn{5}{|l|}{ P. washingtonensis } \\
\hline \multirow{2}{*}{ Thiabendazole } & Pwa 2665 & 1.01 & 25.0 & 30.6 \\
\hline & Pwa 3849 & 4.07 & 62.5 & 124.1 \\
\hline \multirow[t]{2}{*}{ Boscalid } & Pwa 4162 & 4.85 & 75.0 & 91.7 \\
\hline & Pwa 2665 & 23.8 & 100.0 & 100.0 \\
\hline \multirow[t]{2}{*}{ Pyraclostrobin } & Pwa 2525 & 1.06 & 25.0 & 22.5 \\
\hline & Pwa 2665 & 10.7 & 75.0 & 73.4 \\
\hline \multirow[t]{2}{*}{ Pyrimethanil } & Pwa 2665 & 1.86 & 87.5 & 81.8 \\
\hline & Pwa 2649 & 9.83 & 37.5 & 37.6 \\
\hline \multirow[t]{2}{*}{ Difenoconazole } & Pwa 2665 & 2.19 & 0.0 & 0.0 \\
\hline & Pwa 4318 & 14.2 & 0.0 & 0.0 \\
\hline \multirow[t]{2}{*}{ Fludioxonil } & Pwa 2652 & 0.23 & 0.0 & 0.0 \\
\hline & Pwa 2665 & 1.9 & 0.0 & 0.0 \\
\hline \multicolumn{5}{|l|}{ P. pyri } \\
\hline \multirow[t]{2}{*}{ Thiabendazole } & Pp 2491 & 0.04 & 100.0 & 30.3 \\
\hline & Pp 2503 & 2.98 & 100.0 & 30.6 \\
\hline \multirow[t]{2}{*}{ Boscalid } & Pp 2409 & 0.01 & 100.0 & 32.6 \\
\hline & Pp 2481 & 9.48 & 100.0 & 33.1 \\
\hline \multirow[t]{2}{*}{ Pyraclostrobin } & Pp 2481 & 0.01 & 100.0 & 25.4 \\
\hline & Pp 2419 & 2.18 & 100.0 & 26.2 \\
\hline \multirow[t]{2}{*}{ Pyrimethanil } & Pp 2454 & 0.01 & 0.0 & 0.0 \\
\hline & Pp 2418 & 1.62 & 0.0 & 0.0 \\
\hline \multirow[t]{2}{*}{ Difenoconazole } & Pp 2517 & 0.01 & 0.0 & 0.0 \\
\hline & Pp 2371 & 2.97 & 0.0 & 0.0 \\
\hline \multirow[t]{2}{*}{ Fludioxonil } & Pp 2483 & 0.01 & 0.0 & 0.0 \\
\hline & Pp 2418 & 0.85 & 0.0 & 0.0 \\
\hline
\end{tabular}


Leroch et al. 2011). Phacidiopycnis washingtonensis and $P$. pyri are weak and relatively slow-growing pathogens with reduced conidiation in the orchards and storage rooms. Thus, lower risks of FDL resistance development in the future can be expected, which would make it a valuable tool for durable and long-term disease management.

After FDL, PYRI had the lowest mean $\mathrm{EC}_{50}$ values in $P$. washingtonensis and $P$. pyri in vitro, and fully controlled decay on detached fruit after 4 months of storage in a regular atmosphere; however, its efficacy against $P$. washingtonensis started to decrease after 5 months of storage. VF of PYRI in the baseline population was 983, one of the highest among the six tested fungicides, implying a wide sensitivity range within the population. Among the $100 \mathrm{P}$. washingtonensis exposed isolates collected in $2017,5 \%$ were inhibited $<50 \%$ at $0.75 \mu \mathrm{g} / \mathrm{ml}$, whereas only $4 \%$ where inhibited $>75 \%$. Interestingly, $70 \%$ of the exposed $P$. pyri isolates were inhibited more than $75 \%$ by PYRI which may reflect its better in vivo activity against the latter. PYRI has a strong systemic activity compared with many fungicides and it is classified in the medium to high-risk category for fungicide resistance development. It has been used effectively in pome fruit since its registration in 2004. Because of the emerging PYRI resistance in Penicillium expansum (Xiao et al. 2011), recommendation has been to rotate it with FDL on a yearly basis to slow down selection for resistance in P. expansum and B. cinerea, for which resistance has already been reported in several other crops (Amiri et al. 2013; Latorre et al. 2002; Leroux et al. 1999; Myresiotis et al. 2007). In this study, $90 \%$ of the baseline isolates had $\mathrm{EC}_{50}$ values lower than the mean $\mathrm{EC}_{50}$ of $0.32 \mu \mathrm{g} / \mathrm{ml}$. The three isolates tested on detached fruit, however, had an $\mathrm{EC}_{50}>1.8 \mu \mathrm{g} / \mathrm{ml}$. Whether the control failure observed after 5 months is due to PYRI resistance in these isolates or not is unknown and is currently being investigated. Interestingly, the isolate Pwa-2649, with an $\mathrm{EC}_{50}$ of $9.83 \mu \mathrm{g} / \mathrm{ml}$, resulted in speck rot incidence and severity significantly lower than Pwa-2665, with an $\mathrm{EC}_{50}$ of $1.86 \mu \mathrm{g} / \mathrm{ml}$. This likely entails some fitness penalty in isolates with high insensitivity, as was demonstrated previously (Amiri et al. 2014; Myresiotis et al. 2007).

The demethylation inhibitor DFC was registered in 2012 to control powdery mildew and scab in apple orchards and, in 2016, to control postharvest diseases in the PNW. Although, DFC had intermediate mean $\mathrm{EC}_{50}$ values of 1.8 and $1.06 \mu \mathrm{g} / \mathrm{ml}$ for $P$. washingtonensis and $P$. pyri, respectively, it fully controlled all isolates on detached fruit regardless of their $\mathrm{EC}_{50}$ value after 4 and 5 months of storage. Previous studies on other fungal plant pathogens reported a wide range of $\mathrm{EC}_{50}$ values based on the pathogen and the medium used. Thus, the lowest mean $\mathrm{EC}_{50}$ value of $0.002 \mu \mathrm{g} / \mathrm{ml}$ was reported in Venturia inaequalis (Villani et al. 2015), medium mean $\mathrm{EC}_{50 \mathrm{~s}}$ ranging from 0.18 to $0.7 \mu \mathrm{g} / \mathrm{ml}$ were found in Colletotrichum gloeosporioides and C. acutatum (Cao et al. 2017) on PDA, and the highest value of $121.4 \mu \mathrm{g} / \mathrm{ml}$ was reported in Marssonina coronariae on potato carrot dextrose broth medium (Dang et al. 2017). High control efficacy has also been reported for DFC in several pathosystems in vivo or in field conditions (Bartholomäus et al. 2017; Dang et al. 2017; Fonseka and Gudmestad 2016; Munkvold and O'Mara 2002). In pome fruit, DFC is premixed with FDL and registered as Academy (Syngenta Crop Protection). In addition to the high efficacy of FDL and DFC observed in this study, the low and moderate resistance risks of FDL and DFC, respectively, suggest that combining these two active ingredients would constitute a reliable tool to control Phacidiopycnis spp. and other postharvest pathogens if used appropriately. For example, the current recommendations in the PNW are to avoid using the mixture DFC + cyprodinil (Inspire Super) to control powdery mildew in the orchard to avoid selecting for resistant populations of B. cinerea, Neofabraea spp., and Phacidiopycnis spp. and therefore limiting the efficacy of postharvest applications of DFC.

TBZ has been used for decades to control pome fruit postharvest diseases. However, reduced efficacy, implying emerging resistance in B. cinerea (Jurick et al. 2017; Zhao et al. 2010), has resulted in a sharp decrease in TBZ use. Findings from this study suggest that TBZ would not be a reliable tool to control Phacidiopycnis spp. postharvest. Although in vitro $\mathrm{EC}_{50}$ values were not the highest among the six fungicides tested, TBZ failed to provide any control of isolates of both pathogens on detached fruit regardless of their $\mathrm{EC}_{50}$ value. In a single study conducted on Phacidiopycnis pyri, TBZ applied to pear 1 or 10 days after inoculation of stem or calyx ends without wounds reduced Phacidiopycnis rot incidence compared with the control after 5 months of storage (Xiao and Boal 2008). Phacidiopycnis spp. cause disease through stem or calyx ends but also through wounds and fruit-to-fruit contact. Therefore, the inoculation procedure used in our assay does not undermine TBZ efficacy because it was applied preventively and similarly to the other fungicides. BOSC and PYRA had the highest $\mathrm{EC}_{50}$ values and $\mathrm{VF}$ in vitro entailing a wide range of sensitivity in the baseline population, which was confirmed in the exposed population. There was a correlation between the low intrinsic activity of the two active ingredients and their efficacy to control $P$. washingtonensis and $P$. pyri in vivo. If, as suggested, these two species infect fruit mainly in the orchards, the heavy reliance on preharvest applications of Pristine (BOSC + PYRA) in apple and pear orchards since the fungicide was registered may partly explain the emergence and continuous widespread occurrence of these pathogens in the PNW. Additional field studies are warranted to confirm our findings but it is clear that, compared with FDL, PYRI, and DFC, the mixture of BOSC and PYRA as well as thiophanate-methyl are significantly less effective and should not be relied upon preharvest.

In this study, the baseline sensitivities of $P$. washingtonensis and $P$. pyri have been established to all pre- and postharvest fungicides used in pome fruit. The baseline values will be useful in future sensitivity monitoring to detect potential shifts toward resistance. We have also established the efficacy and assessed the activity of current fungicides, which should facilitate scientifically based management of these two quarantined pathogens and limit future epidemics.

\section{Acknowledgments}

This work was supported, in part, by the Washington Tree Fruit Research Commission. PPNS number 0748, Department of Plant Pathology, College of Agricultural, Human, and Natural Resource Sciences, Agricultural Research Center, Hatch Project Number WNP0555, Washington State University, Pullman 99164-6430.

\section{Literature Cited}

Amiri, A., Brannen, P. M., and Schnabel, G. 2010. Reduced sensitivity in Monilinia fructicola field isolates from South Carolina and Georgia to respiration inhibitor fungicides. Plant Dis. 94:737-743.

Amiri, A., Heath, S. M., and Peres, N. A. 2013. Phenotypic characterization of multifungicide resistance and in Botrytis cinerea isolates from strawberry fields in Florida. Plant Dis. 97:393-401.

Amiri, A., Heath, S. M., and Peres, N. A. 2014. Resistance to fluopyram, fluxapyroxad, and penthiopyrad in Botrytis cinerea from strawberry. Plant Dis. 98:532-539.

Amiri, A., Mulvaney, K. A., and Pandit, L. K. 2017. First report of resistance to fluxapyroxad and fluopyram in Botrytis cinerea from commercial apple orchards in Washington State. Plant Dis. 101:508.

Bartholomäus, A., Mittler, S., Märländer, B., and Varrelmann, M. 2017. Control of Rhizoctonia solani in sugar beet and effect of fungicide application and plant cultivar on inoculum potential in the soil. Plant Dis. 101:941-947.

Brooks, F. T. 1928. On the occurrence of Phacidiella discolor (Mout. \& Sacc.) potebnia in England. Trans. Br. Mycol. Soc. 13:75-81.

Cannon, P. F., Hawksworth, D. L., and Sherwood-Pike, M. A. 1985. The British Ascomycotina. An Annotated Checklist. Commonwealth Mycological Institute, Slough, UK.

Cao, X., Xu, X., Che, H., West, H. S., and Luo, D. 2017. Distribution and fungicide sensitivity of Colletotrichum species complexes from rubber tree in Hainan, China. Plant Dis. 101:1774-1780.

Dang, J. L., Gleason, M. L., Niu, C. K., Liu, X., Guo, Y. Z., Zhang, R., and Sun, G. Y 2017. Effects of fungicides and spray application interval on controlling Marssonina blotch of apple in the Loess plateau region of China. Plant Dis. 101:568-575.

Dennis, R. W. G. 1978. British Ascomycetes, 2nd ed. J. Cramer, Vaduz, Liechtenstein.

Díaz, G. A., Zoffoli, J. P., Lolas, M., Blanco, A., Latorre, B. A., Ferrada, E. E., Elfar, K., and Naranjo, P. 2016. Occurrence of Phacidiopycnis washingtonensis causing speck rot on stored pink lady apple fruit in Chile. Plant Dis. 100:211.

DiCosmo, F., Nag Raj, T. R., and Kendrick, W. B. 1984. A revision of the Phacidiaceae and related anamorphs. Mycologue Publications, Waterloo, ON, Canada.

Elliott, M., Chastagner, G. A., Coats, K. P., Sikdar, P., and Xiao, C. L. 2014. First report of a new leaf blight caused by Phacidiopycnis washingtonensis on Pacific madrone in western Washington and Oregon. Plant Dis. 98:1741.

Fernández-Ortuño, D., Chen, F., and Schnabel, G. 2013. Resistance to cyprodinil and lack of fludioxonil resistance in Botrytis cinerea isolates from strawberry in North and South Carolina. Plant Dis. 97:81-85. 
Ficke, W., and Agraring, E. P. 1982. Über das Vorkommen in der DDR Bisher nicht nachgewiesener Rindenbranderreger am Apfel [About the occurrence of apple bark necrosis pathogens so far not identified in the GDR]. Arch. Phytopathol. Plant Prot. 18:31-38.

Fonseka, D. L., and Gudmestad, N. C. 2016. Spatial and temporal sensitivity of Alternaria species associated with potato foliar diseases to demethylation inhibiting and anilino-pyrimidine fungicides. Plant Dis. 100:1848-1857.

Garibaldi, A., Bertetti, D., Amatulli, M. T., and Gullino, M. L. 2010. First report of postharvest fruit rot in persimmon caused by Phacidiopycnis washingtonensis in Italy. Plant Dis. 94:788.

Giraud, M., Westercamp, P., Coureau, C., Chapon, J. F., and Berrie, A. 2001. Recognizing Postharvest Diseases of Apple and Pear. Ed. Ctifl, Paris.

Hilber, U. W., and Schüepp, H. 1996. A reliable method for testing the sensitivity of Botryotinia fuckeliana to anilinopyrimidines in vitro. Pestic. Sci. 47:241-247.

Hu, M. J., Luo, C. X., Grabke, A., and Schnabel, G. 2011. Selection of a suitable medium to determine sensitivity of Monilinia fructicola mycelium to SDHI fungicides. J. Phytopathol. 159:616-620.

Jurick, W. M. I., Macarisin, O., Gaskins, V. L., Park, E., Yu, J., Janisiewicz, W., and Peter, K. A. 2017. Characterization of postharvest fungicide-resistant Botrytis cinerea isolates from commercially stored apple fruit. Phytopathology 107:362-368.

Kim, Y. K., and Xiao, C. L. 2006. A postharvest fruit rot in apple caused by Phacidiopycnis washingtonensis. Plant Dis. 90:1376-1381.

Latorre, B. A., Spadaro, I., and Rioja, M. E. 2002. Occurrence of resistant strains of Botrytis cinerea to anilinopyrimidine fungicides in table grapes in Chile. Crop Prot. 21:957-961.

Leroch, M., Kretchmer, M., and Hahn, M. 2011. Fungicide resistance phenotypes of Botrytis cinerea isolates from commercial vineyards in South West Germany. J. Phytopathol. 159:63-65.

Leroux, P., Chapeland, F., Desbrosses, D., and Gredt, M. 1999. Patterns of crossresistance to fungicides in Botryotinia fuckeliana (Botrytis cinerea) isolates from French vineyards. Crop Prot. 18:687-697.

Liu, Q., and Xiao, C. L. 2005. Influence of nutrient and environmental factors on conidial germination of Potebniamyces pyri. Phytopathology 95:572-580.

Munkvold, G. P., and O'Mara, J. K. 2002. Laboratory and growth chamber evaluation of fungicidal seed treatments for maize seedling blight caused by Fusarium species. Plant Dis. 86:143-150.

Myresiotis, C. K., Karaoglanidis, G. S., and Tzavella-Klonari, K. 2007. Resistance of Botrytis cinerea isolates from vegetable crops to anilinopyrimidine, phenylpyrrole, hydroxyanilide, benzimidazole, and dicarboximide fungicides. Plant Dis. 91: 407-413.
Potebnia, A. 1912. Ein neuer Krebserreger des Apfelbaumes Phacidiella discolor (Mout. Et Sacc.) A. Pot., seine Morphologie und Entwickelungsgeschichte. Z. Pflanzenkrank. 22:129-153.

Sharma, R. L. 1991. Prevalence of storage rots of China pear in Himachal Pradesh. Plant Dis. Res. 5:109-111.

Sholberg, P. L., Stokes, S. C., and O'Gorman, D. T. 2010. First report of Phacidiopycnis rot of pears caused by Potebniamyces pyri (anamorph Phacidiopycnis piri) in British Columbia. Can. J. Plant Pathol. 32:334-341.

Sikdar, P., Mazzola, M., and Xiao, C. L. 2013. Phacidiopycnis washingtonensis: Inoculum availability, persistence and seasonal host susceptibility in Washington apple orchards. (Abstr.) Phytopathology 103:S2.133.

Snowdon, A. L. 1990. Pome fruits, apples and pears. Pages 170-216 in: PostHarvest Diseases and Disorders of Fruits and Vegetables: Vol. 1: General Introduction and Fruits. CRC Press Inc., Boca Raton, FL.

Southee, E. A., and Brooks, F. T. 1926. Notes on a pycnidial fungus associated with a dying back of apple branches. Trans. Br. Mycol. Soc. 11:213-219.

Villani, S. M., Biggs, A. R., Cooley, D. R., Raes, J. J., and Cox, K. D. 2015. Prevalence of myclobutanil resistance and difenoconazole insensitivity in populations of Venturia inaequalis. Plant Dis. 99:1526-1536.

Weber, R. W. S. 2011. Phacidiopycnis washingtonensis, cause of new storage rot of apples in Northern Europe. J. Phytopathol. 159:682-686.

Xiao, C. L., and Boal, R. J. 2002. Pathogenicity and infection courts of Phacidiopycnis piri in pears. (Abstr.) Phytopathology 92:S88.

Xiao, C. L., and Boal, R. J. 2004. Prevalence and incidence of Phacidiopycnis rot in d'Anjou pears in Washington State. Plant Dis. 88:413-418.

Xiao, C. L., and Boal, R. J. 2008. Control of Phacidiopycnis rot in 'd'Anjou' pears. Acta Hortic. 800:935-940.

Xiao, C. L., Kim, Y. K., and Boal, R. J. 2009. A new canker disease of crabapple trees caused by Phacidiopycnis washingtonensis in Washington State. Online publication. Plant Health Prog. doi.org/10.1094/PHP-2009-0612-01-BR

Xiao, C. L., Kim, Y. K., and Boal, R. J. 2011. First report of occurrence of pyrimethanil resistance in Penicillium expansum from stored apples in Washington State. Plant Dis. 95:72.

Xiao, C. L., Rogers, J. D., Kim, Y. K., and Liu, Q. 2005. Phacidiopycnis washingtonensis-A new species associated with pome fruits from Washington State. Mycologia 97:464-473.

Zhao, H., Kim, Y. K., Huang, L., and Xiao, C. L. 2010. Resistance to thiabendazole and baseline sensitivity to fludioxonil and pyrimethanil in Botrytis cinerea populations from apple and pear in Washington State. Postharvest Biol. Technol. 56:12-18. 